\title{
The Hidden Proceedings - An Analysis of Accountability of Child Protection Adoption Proceedings in Eight European Jurisdictions
}

\author{
Kenneth Burns \\ Senior Lecturer, School of Applied Social Studies, University College Cork, \\ Ireland \\ k.burns@ucc.ie \\ Katrin Križ \\ Professor, Department of Sociology, Emmanuel College Boston, USA \\ krizka@emmanuel.edu \\ Jenny Krutzinna \\ Postdoctoral Researcher, Centre for Research on Discretion and Paternalism, \\ University of Bergen, Norway \\ jenny.krutzinna@uib.no
}

\section{Katre Luhamaa}

Researcher, Centre for Research on Discretion and Paternalism,

University of Bergen, Norway

katre.luhamaa@uib.no

\section{Thomas Meysen}

Managing Director, International Centre for Socio-Legal Studies, Germany meysen@socles.de

\author{
Tarja Pösö \\ Professor, Tampere University, Finland; \\ Professor, Centre for Research on Discretion and Paternalism, \\ University of Bergen, Norway \\ tarja.poso@tuni.fi
}

\section{Sagrario Segado}

Associate Professor, National Distance Education University, Spain ssegado@der.uned.es 


\author{
Marit Skivenes* \\ Professor, Centre for Research on Discretion and Paternalism, \\ University of Bergen, Norway \\ marit.skivenes@uib.no \\ June Thoburn \\ Emeritus Professor, School of Social Work, University of East Anglia, UK \\ j.thoburn@uea.ac.uk
}

\begin{abstract}
How accountable are decisions about terminating parental rights to ensure an adoption from care? In this paper we examine if the proceedings in eight European jurisdictions are accountable to: a) the private parties, i.e. individuals that are concerned such as parents, child; b) the general public that authorized the politicians and the government to make legislation; and c) the elected government, i.e. the legislators and the system that have granted the court, court-like or administrative body the authority to make these decisions. Our data material consists of national legislation, organizational guidelines (courts, child protection, or supervisory agencies), statistics and expert knowledge. The conclusions of our analysis are discouraging. There is only limited accountability for one of the most intrusive interventions by a state into the private lives of individuals. There is a lack of information about the proceedings as well as a lack of transparency. We identify systems that, with few exceptions, operate in isolation, with only a few outsiders having access or knowledge about what is going on. We cannot in this study say anything about the decision-making quality in these proceedings, they may be excellent, but the problem is that very few external actors are in a position to examine the quality of the decisions. This missing connection between the wider democratic society and this part of the legal systems in the eight democracies we studied is of huge concern, and we have indications that the situation is equally concerning in other European states.
\end{abstract}

\title{
Keywords
}

accountability - adoption proceedings - court jurisdictions - cross-country comparison

* Corresponding author. 
The aim with this paper is to investigate accountability and transparency mechanisms in adoption proceedings. All European countries provide a legal opportunity to terminate parental rights and place a child for adoption without parents' consent. ${ }^{1}$ Typically, it is the judiciary system that is vested with the authority to make these decisions, which requires justifiable and rational reasons due to the gravity of state intervention and the associated restrictions of individuals' freedom. There is significant variation across countries on how adoption from care is conducted and practiced. ${ }^{2}$ While in England approximately 4 children per 10,000 children are adopted from care each year, in Finland it is one such adoption each year. The typical starting point for any adoption from care is that parental rights will have already been restricted and custodial responsibility for the child will be placed with the state, i.e. the child protection system. This may or may not affect all parental rights, and consent issues may arise where limited rights remain with the birth parents, as the court will have to ask for consent, or further curtail or terminate parental rights to dispense with parental consent requirements. The child's best interests principle is the foundation for all adoption decisions, but it is a principle that is immensely difficult to apply in decision-making ${ }^{3}$ and that gives great discretionary power to decision makers. In this paper, we examine how these

** This project has received funding from the European Research Council (ERC) under the European Union's Horizon 2020 research and innovation programme (grant agreement no. 724460) and from the Research Council of Norway under the Independent Projects Humanities and Social Science program (grant no. 262773). We are grateful for constructive comments from all reviewers. Thanks also to research assistant F. Wingens for help with editing.

1 C. Fenton-Glynn 'Adoption Without Consent,' Study for the PE TI Committee (2015). Retrieved o8 May 2019. http://www.europarl.europa.eu/RegData/etudes/STUD/2015/519236/IPOL_STU (2015)519236_EN.pdf. We define 'adoptions from care' as those cases where a child is the responsibility of the child protection system and is placed in state care or is under guardianship of the state, after full or partial removal of custody from the parents, is freed for adoption or adopted with or without the consent of the parents.

2 K. Burns, T. Pösö and M. Skivenes, Child Welfare Removals by the State: A Cross-Country Analysis of Decision-Making Systems (Oxford University Press 2017).

3 J. Elster, Ulysses and the Sirens: Studies in Rationality and Irrationality (Cambridge, UK: Cambridge University Press, 1979); R. Mnookin and E. Szwed, 'The Best Interests Syndrome and the Allocation of Power in Child Care', in: H. Geach and E. Szwed (eds), Providing Civil Justice for Children (London, UK: Edward Arnold) 7-20. 
decision makers and their decisions are being held accountable. ${ }^{4}$ Adequate mechanisms of accountability become most critical where the power differential between the involved parties is greatest, such as between the state and an individual, and where any actions or interventions have serious and/or irreversible consequences for individuals - as is the case in adoptions of children from state care.

As a first step to shed light on this theme, we examine the required proceedings to undertake an adoption from care in eight high-income European countries that differ in terms of child protection system and legal order: Austria, England, Estonia, Finland, Germany, Ireland, Norway and Spain. We focus on the proceedings and the decision-making bodies that have the authority to decide about an adoption from care. ${ }^{5}$ We inquire if the procedures that should be followed to decide whether to grant an adoption or not are accountable to: a) the private parties, i.e. individuals that are concerned - such as parents, child; b) the general public that authorized the politicians and the government to make legislation; and c) the elected government, i.e. the legislators and the system that have granted the court, court-like or administrative body the authority to make these decisions.

To study the accountability of adoption proceedings in eight jurisdictions, we examined relevant legislation for terminating parental rights and adoption decision-making, including information about the composition of the decision-making bodies that are vested with the authority to make these decisions. The paper does not examine the experiences of participants in the individual proceedings.

The structure of the paper is as follows: first, we define the concept of accountability and apply it to the particular context of child protection and adoptions from care. Second, we provide the relevant background on adoptions from care in the eight countries studied. This is followed by an outline of our methods and an overview of data material. In the findings section, we then present the specific situation according to accountability mechanisms in each

4 M. Bovens, 'Analysing and Assessing Accountability: A Conceptual Framework' European Law Journal 13(4) (2007) 447 at 468. And G. Brandsma and T. Schillemans, 'The Accountability Cube: Measuring Accountability' Journal of Public Administration Research and Theory 23(4) (2012) 953-975. And K. Lowande, 'Who Polices the Administrative State?' American Political Science Review 112(4) (2018) 874-890.

5 For simplicity, we use the term decision or judgement to characterize an adoption order by a court or the decision by a decision-making body that have the formal authority to make this type of decision. Thus, we do not include the various country specific legal terms for interventions in each of the eight legal systems. For the same reason we also use the term court or judiciary for including boards and other court alike decision-making bodies. 
of the eight systems. Finally, we discuss our findings, and provide our conclusion as to the accountability in adoptions from care as part of state interventions into the family and children's rights in the eight European countries. We present a detailed overview of information and sources as online supplementary appendix. ${ }^{6}$

\section{Accountability, Transparency and Child Protection}

Accountability is ".... relationship between an actor and a forum, in which the actor has an obligation to explain and to justify his or her conduct, the forum can pose questions and pass judgement, and the actor may face consequences." ${ }^{7}$ In addition, the concept contains several layers that interplay in an assessment of the adequacy of any particular accountability regime. ${ }^{8}$ Bovens refers to these layers as "perspectives", of which he identifies three: a democratic, a constitutional and a learning perspective. While the democratic perspective allows for popular control, the constitutional perspective aims to provide a checks and balances system to prevent the abuse of power, and the learning perspective focuses on enhancing government effectiveness. In the present context of child protection adoptions, these perspectives are necessary aspects of any legitimate state intervention; accountability ultimately helps to ensure the legitimacy of governance. ${ }^{9}$ To achieve accountability, public debate, transparency and information are core elements. In the theory of public discourse, the public sphere represents (at least) three types of idealizations: ${ }^{10}$ first, position and status are eliminated, so that arguments and reasons are influential and decisive; second, there are no limitations in regard of which issues can be raised and problematized; and, third, it opens up for general inclusion - everyone can, in principle, participate. Today, there are many forums where citizens can freely debate and provide reasons for decisions on issues of concern, but there is also a tendency for such debates to be held within the "in group" and less as real adversarial discussions, a phenomenon that weakens the basis for rational debate.

\footnotetext{
6 https://www.discretion.uib.no/projects/supplementary-documentation/.

7 M. Bovens 450.

8 H. Bergsteiner and G. Avery, 'A Generic Multiple Constituency Matrix: Accountability in Private Prisons' Journal of Public Administration Reesearch and Theory 19(3) (2009) 631-66o.

9 M. Bovens 464.

10 J. Habermas, Reason and the Rationalizing of Society (Boston, MA: Beacon Press).
} 


\subsection{Transparency}

Governments and public administrations have an obligation to be transparent about their activities, which is typically regulated in a national information act and derives, inter alia, from Article 11 of the European Charter of Fundamental Rights. This is the precondition for having control over the institutions and procedures that shall be just and safe for the citizens. The four reasons for transparency are key premises for accountability: influence, control, rule of law, and information. The first two are the most important, i.e. citizens should be able to exert influence and control. Influence for us as citizens is about the public being able to engage in open and free opinion-making processes that should not be manipulated and ruled by the state and the authorities' thinking and regulation. It is through discussions in civil society, where opinions are expressed and ideas are developed, that perceptions about what will be the state's task are created. The public sphere's function is to identify and clarify for which problems there should be a societal responsibility to solve them. In this way, the people, not just the parties, lobbyists or monetary players, will be the premier supplier in designing policy. This is the input side of democracy and is central to democratic governance. Control over the exercise of authority and the content of public policy is important, because the public administration implements policies of great importance for people. There is also a need for follow-up of what is being done or not done, i.e. the output side of the government is vital. ${ }^{11}$ Politics is designed in line with established and formulated goals and visions. Important questions are whether adequate consideration has been given to relevant arguments and knowledge, whether the resources are used in a sensible way, and especially if the state operates in accordance with legal principles and statutes. As Featherstone et al. ${ }^{12}$ have explained, "the concept of the just culture requires minimally that an organization has an accessible memory - which means it has to have a mechanism for the honest reporting of inadvertent errors and systemic problems." The control dimension is easily recognizable in media reports, which are very

11 B. Rothstein, The Quality of Government Corruption, Social Trust, and Inequality in International Perspective (Chicago, IL: University of Chicago Press 2011); K. Lowande, 'Who Policies the Administrative State?, American Political Science Review 112(4) (2018) 874-890.

12 B. Featherstone, K. Morris and S. White, Re-imaging Child Protection: Towards Humane Social Work with Families (Bristol, UK: Policy Press 2014) 76. 
often about how something has gone wrong. Two other considerations are also expressed as important for transparency, and that is rule of law and access to information. Rule of law is supported by transparency because it means that people can investigate the administration's law enforcement and practices. There are surely mechanisms and agencies that are more important for safeguarding citizens' legal rights, but with the government's exercise of authority, openness is an important means of securing protection from the abuse of authority. Finally, governments have large amounts of information that is often of high quality, and this is a resource that should be considered a common good and desirable that anyone can use it. Access to good information will also help the participants in forming debates and ensure political processes are informed.

In the context of public administration, transparency is not straightforward for at least two reasons: First, where sensitive information or data is concerned, as in the case of adoption, particular care has to be taken to ensure confidentiality, which may render the involvement of the public challenging; and second, the courts maintain an independent position in a constitutional democracy and are thus shielded from direct scrutiny by a forum. However, such considerations should not be understood as an argument against transparency, but rather as a reminder of the need for some safeguards to protect individual rights. For accountability purposes, the use of de-identified information would be sufficient, thus avoiding the sharing of highly-sensitive personal data.

\subsection{Accountability in Practice}

Consequently, the definition of accountability and its constitutive criteria that we have outlined above, must be adjusted to the realities of the child protection system and the courts. We thus define the actor as the decision-making bodies, i.e. the courts themselves (single judge, panel of judges) or any courtlike or administrative bodies. The forum can be defined as a) the government, b) the public (i.e. citizens, the media), and c) the concerned parties in any particular case. Bovens' definition has three constitutive elements: The first is the obligation to inform the forum, which can take the form of an oral or a written decision, explanations of the procedures that must be followed, and publicly available anonymized written decisions. The second is the requirement of the "... possibility for the forum to interrogate the actor and to question the adequacy of the information or the legitimacy of the conduct". The courts and the judiciary decision-makers are not directly obliged to justify or explain their actions to a forum, because the courts in a constitutional democracy are independent and thus cannot be instructed. However, the legal 
system is hierarchical, and appeal courts may revise and change a decision. The third condition, namely the possibility for the forum "to pass judgement on the conduct of the actor", ${ }^{13}$ is more complicated, as adoption decisionmaking bodies that are courts cannot be directly sanctioned by legislators, and it would not be legitimate to impose any sanctions on the court in a functioning democracy. ${ }^{14}$ However, if the forum is not satisfied with the practice of the decision-making bodies, the political part of the government can issue new legislation or regulations, a concerned party in a case can appeal a decision, and citizens may use the public sphere and the media to express their dissatisfaction and to effect change, as illustrated by reference to highly publicised stories about child protection systems. ${ }^{15}$ We operationalize these criteria in the next section.

\section{Accountability in Adoption From Care}

Child protection proceedings concerning adoptions without parental consent constitute one of the most serious state interventions in private and family life, with serious and typically irreversible consequences for the parties involved. It is therefore crucial that the decision-making bodies and decision-makers render an account of their decisions. The legal foundation for adoptions from care, with or without parental consent, is the starting point for our analysis, including the proceedings to be followed before such an adoption is granted and the decision-making body with the authority to make these decisions. Based on this, we examine to what extent the decisions are documented for an accountability forum, whether explanations and justifications are provided, and if the possibility for questions, judgments and consequences for the actor are present. We have operationalized these questions into seven criteria for the assessment of accountability, see Table 1:

Having defined the concept of accountability in the context of child protection proceedings and the relevant seven assessment criteria, we now turn to the context of legal proceedings for adoptions from care in the eight countries.

\footnotetext{
13 Bovens (2007), p. $45^{2}$.

14 Ibid.

15 British Broadcasting Corporation (ввс), 'Norway's Hidden Scandal' (o3 August 2018) retrieved 15 May 2019 https://www.bbc.co.uk/news/resources/idt-sh/norways_hidden_ scandal.
} 
TABLE 1 Operationalized criteria for our assessment of accountability

$1 \quad$ Format of proceedings: Do the proceedings involve a hearing in which the parties concerned (public and private) are present and argue their case and meet the decision makers when a judgement is announced? Or, is it a process whereby the decision makers meet each party concerned individually, and review and decide based on these testimonies and written material presented? Furthermore, may there be an observer present at the proceedings (researcher or journalist)? Are there recordings of the proceedings?

2 Decision format: Are decisions preserved for potential scrutiny? Are the judgments delivered orally or in writing, and are they recorded? Who decides, whether and when a decision is delivered in writing? What is discussed as part of the decision?

3 Recipients of decisions: Who are the written court judgements (if any) written for? Are the judgements written for the parties involved, the parents and the child? Are the judgements written for the general public, or for researchers and journalists? Are the judgements written for the legal community, including the appellate courts, and the experts in the field of child protection and family issues?

4 Reasoning: Do the records of the decisions include the reasoning behind them? Does the decision maker explain and justify the decision, a) by reference to the applicable law, and b) by application of the law to the facts of the case, and to the principle of the child's best interests? Is the reasoning substantial and or is it only a summary?

$5 \quad$ Appeal: Can adoption decisions be appealed? Who has the right to appeal? What is the extent of the appeal (full review or narrow review)? Which body reviews the appeal? What is the format of the appeal proceedings (written or with a hearing)?

6 Public availability of decisions: Are the judgements publicly available, and if yes, in what format and for whom? Is it a synopsis of the judgment, or the judgement in full? Are the judgments anonymized? Is it a delayed publication of judgments, for example available after a time period? Who decides which decisions are made public?

7 Practical obstacles: Are there any barriers to accessing the formal proceedings, such as, for example, the high cost of legal support and lack of legal aid, effectively restricting accountability for all practical purposes? 
Our study examines eight European countries - Austria, England, Estonia, Finland, Germany, Ireland, Norway and Spain - that differ in regard of child protection system, ${ }^{16}$ welfare state model, ${ }^{17}$ ranking on sustainable development goals for adults and for children, ${ }^{18}$ and recognition of children's rights ${ }^{19}$ and access to justice. ${ }^{20}$ In regard of the proceedings on adoption from care, country differences are to be expected, although the Council of Europe has aimed at unifying the adoption process through the European Convention on the Adoption of Children (Revised) of 2008. Out of the eight countries we examine, four are members to the Convention (Finland 2012, Germany 2015, Norway 2011, and Spain 2011), the United Kingdom has signed the Convention but not ratified it (2008), and the three other countries are not members to it (Austria, Estonia and Ireland). The European Adoption Convention allows adoptions only in the best interests of the child, with the aim of providing the child with a stable and harmonious home. It also stresses that the prerequisite for adoption should be the consent of the parents. ${ }^{21}$ Even though the number of parties to the Convention is low, it has received recognition as the European standard in a number of judgments of the European Court of Human Rights, as adoption is also covered by Article 8 (right to respect for private and family life) of the European Convention on Human Rights.

Adoptions from care are typically decided by the judiciary, but decisions may also be made by a court-like or administrative body (Ireland, Norway, Spain), rather than a general (Austria, Estonia, Finland) or specialist court (England, Germany).

16 Burns et al. 2017; N. Gilbert, N. Parton and M. Skivenes, Child Protection Systems: International Trends and Orientations (Oxford University Press 2011).

17 W. Arts and J. Gelissen, 'Three Worlds of Welfare Capitalism or More? A State-of-the-Art Report' Journal of European Social Policy 12 (2) (2002) 137 at 158; G. Esping-Andersen, The Three Worlds of Welfare Capitalism (Princeton, NJ: Princeton University Press 1990).

18 United Nations General Assembly [2015] 'Resolution 70/1 Adopted by the General Assembly on 25 September 2015'; UnICEF 'The 2030 Agenda for Sustainable Development.' UNICEF and the SDGs. o7 September 2016. Retrieved 26 August 2019 https://www.unicef .org/agenda2030/69525.html.

19 KidsRights Foundation [2019], 'The KidsRights Index' Retrieved 26 August 2019 https:// www.kidsrightsindex.org/.

20 Child Rights International Network, 'Rights, Remedies \& Representation: Global Report on Access to Justice for Children' (London, UK: Child Rights International Network 2016).

21 Council of Europe Treaty Series - No. 202 [2008], 'European Convention on the Adoption of the Child (Revised)' Art 5 (1a) 27 November 2008. 
TABLE 2 The child's consent to adoption (See appendix \#1 for details on sources)

\section{Country Child's consent requirements}

$\begin{array}{ll}\text { Estonia } & \text { Strict age limit of } 10 \\ \text { Norway } & \text { Strict age limit of } 12 \\ \text { Spain } & \text { Strict age limit of 12, and younger children if considered mature enough } \\ \text { Finland } & \text { Age limit of 12, and younger children if considered mature enough } \\ \text { Germany } & \text { Strict age limit of } 14 \\ \text { Austria } & \text { Age limit of } 14 \\ \text { England } & \text { No consent criteria, but child's ascertainable wishes } \\ \text { Ireland } & \text { No consent criteria, but child has an entitlement to be heard }\end{array}$

The requirement for the child to consent to an adoption varies between countries, and the European Adoption Convention, Art. 5(1)(b) states that ".... a child shall be considered as having sufficient understanding on attaining an age which shall be prescribed by law and shall not be more than 14 years...", unless it would be contrary to the child's best interests. This has been implemented differently in the eight countries studied. ${ }^{22}$

Besides any procedural differences, there is also significant variation in the number of adoptions from care, ${ }^{23}$ although obtaining comparable statistics is challenging due to the different reporting parameters. ${ }^{24}$ Furthermore, for some adoptions that are initially opposed by the parent(s), consent is eventually given during the adoption process; sometimes these cases are consequently defined as 'voluntary' in the statistics, and sometimes they are defined as 'involuntary'. In Austria, England, Germany and Norway, all cases are decided

22 See Table 2 below; cf. C. Fenton-Glynn, 'The Child's Voice in Adoption Proceedings: A European Perspective' The International Journal of Children's Rights 21(4) 590.

23 See table 3 below.

24 Statistical material may lack a clear distinction between adoptions with or without parental consent; consent may signify merely that parents do not oppose the adoption plans proposed by the CPS; and systems differ in regard to the responsibilities of the CPS or another part of the state. There is not much research on the distinction between consent and non-consent, and how consent is obtained, nor on why parents give consent, or why some cases are defined as consent and others are not. It may be the case, for instance, that parents know their chances for reunification with their child are minimal and decide themselves that all things considered adoption is in the child's best interests, or they may be 'nudged' into agreeing to the adoption by professionals. 
TABLE 3 Children adopted from care in eight jurisdictions. Sources in Appendix, \#2

\begin{tabular}{lccc}
\hline Country & $\begin{array}{l}\text { Adoptions from } \\
\text { care (2016) }\end{array}$ & $\begin{array}{l}\text { Per 10,0oo } \\
\text { children }\end{array}$ & $\begin{array}{l}\text { Child population } \\
(\mathbf{2 0 1 6 )}\end{array}$ \\
\hline Austria & 93 & 0.6 & $1,519,316$ \\
England & 4,350 & $3 \cdot 7$ & $11,785,311$ \\
Estonia & 38 & 1.4 & 271,383 \\
Finland & 3 & - & $1,131,328$ \\
Germany & 661 & 0.50 & $13,325,677$ \\
Ireland & 19 & 0.16 & $1,190,502$ \\
Norway & 60 & 0.51 & $1,178,920$ \\
Spain & 588 & 0.66 & $8,936,533$ \\
\end{tabular}

by the court regardless of consent, thus somewhat remedying the insecurity around the circumstances of the consent and whether it is fully informed.

\section{$5 \quad$ Method and Data Material}

The basis of our current research is the national legislation, organizational guidelines (courts, child protection, or supervisory agencies), statistics and expert knowledge of the eight high-income European countries. The national experts of each country, with access to the native language, should provide information on legislation and procedural guidelines, the child protection system and adoption proceedings. An extensive overview of the adoption proceedings for each country is also presented as online supplementary material. ${ }^{25}$

We apply our operationalisation of Bovens' framework into seven themes ${ }^{26}$ and our presentation of country findings follows these themes. There are limitations with this approach: we do not use information from the decisionmakers themselves, nor do we include information from the parties concerned and their legal representatives, who would have insight into the actual practice and the deficits (and strengths) of the respective system. However, in other parts of the project we focus on these experts, and our analysis herein makes a contribution to knowledge on adoption practices within these countries. This paper cannot do full justice to all the legal and procedural specifics of

25 https://www.discretion.uib.no/resources/adoption-from-care-proceedings.

26 Cf. table 1. 
each of the eight jurisdictions, and each of the legal systems under study, due to limitations of the article format. We utilized secondary materials (reports, commentaries, etc.) based on the time they were published, and we consulted legal scholars and experts in each of the countries to ensure that our analysis is accurate. Where regional variations of national laws and procedures exist in a country (e.g. due to federalism), we have limited ourselves to providing specific legislative examples from one administrative region.

\section{$6 \quad$ Findings}

For each of the eight countries, we provide a brief general overview of the adoption process, followed by a mapping of each country's adoption decisionmaking system onto the seven accountability criteria, namely, format of proceedings (incl. parties heard), decision format (incl. subject matters discussed), recipients of decisions, reasoning, appeal, public availability of decisions, and practical obstacles. ${ }^{27}$

\subsection{Austria}

The Austrian Civil Code (АВGв) provides that "the adoption of a minor child shall be granted if it serves the child's well-being, and if a relationship [between the child and her or his adoptive parents] has been established or should be established." 28

Although typically consent-based, an adoption may occur without parental consent if the location of the parents is not known for at least six months or they are incapacitated for longer than a temporary time period. ${ }^{29}$ The law also stipulates that the court shall replace consent that was refused by the parents "if there are no justified reasons for the refusal." ${ }^{30}$ Adoption proceedings are held at the district court, presided on by a judge with expertise in family law. These hearings are typically closed to the public. The minor adoptive child, the parents of a child who has reached legal majority, the foster parents or manager of the residential home where the child resides, and the child protection services all have the right to be heard in court. ${ }^{31}$ Prospective adoptive parents that are not the current foster parents do not have a right to be heard in court.

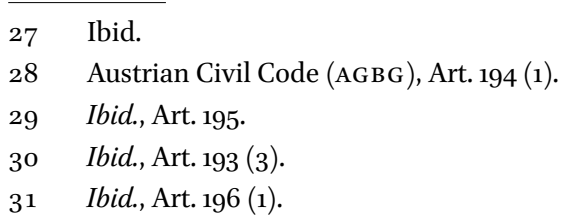


If the child is not able to provide a statement, or the hearing would endanger the child's well-being, the child's right to be heard is dispensed with. ${ }^{32}$

The preparation for the adoption is undertaken by the child protection agency, which involves advising and guiding the birth parents; advising, preparing, assessing and training the adoptive parents, and choosing suitable adoptive parents based on the child's needs. ${ }^{33}$ The suitability of the adoptive parents is assessed by two professionals of the child protection services agency. ${ }^{34}$ Once suitable adoptive parents have been identified, the birth parents need to grant permission. Their declarations of consent must be delivered to the court in person, but consent may be revoked up until the court decision. ${ }^{35}$ The child protection agency prepares the adoption contract between the child and the adoptive parent(s), but the adoption only becomes effective if approved by a court. ${ }^{36}$

The judge relies on the hearing with the parties involved and the report provided by the child protection agency. This includes background information about the child and the parents, documents the parents' agreement with the adoption, and provides evidence that the child has developed a relationship with her future adoptive parents that is or could be akin to a child-parent relationship. Before the court hearing, the judge may meet with the birth and adoptive parents, and the child if this is deemed necessary. The decision on adoption and termination of birth parents' parental rights is written by the judge. This document, typically three to four pages long, is sent to the involved parties and contains the name of the court and judge, date of the decision, the decision made by the judge (adoption granted or not), followed by information about the birth and adoptive parents and the child, the date when the decision goes into effect and the reasoning behind the decision. The latter provides some background information about the child's care trajectory leading to the adoption and explains the reasoning with reference to the law. The decision can be appealed to the next instance court within 14 days, but only for very significant legal reasons. ${ }^{37}$ Court decisions about adoptions are not publicly available; however, they may be accessed in de-identified form for research

$32 \quad$ Ibid., Art. $196(2)$.

33 See, for instance, the Child Welfare Law of Vienna [2013], Art 50.

34 Ibid., Art. $5^{2}$ (1); MAG ELF, 'Qualitätshandbuch. Soziale Arbeit mit Familien (Vienna, AUT: City of Vienna 2016).

35 Art. 87 of the Non-Contentious Proceedings Act (Außerstreitgesetz).

36 Austrian 'Bundeskanzleramt' [2019] 'Ablauf der Adoption' o1 January 2019 Retrieved 26 August 2019 https://www.help.gv.at/Portal.Node/hlpd/public/content/72/Seite.720003 .hmtl. 
purposes upon discretionary approval by the Ministry of Justice. This may entail a cost for anonymization. The Supreme Court publishes decisions about appeals on the Rechtsinformationssystem des Bundes (RIS), and a few court cases of second instance courts are also available in anonymised form.

\subsection{England}

The principal legislation is the Adoption and Children Act 2002 (as amended) (ACA), which is closely aligned with the England and Wales Children Act 1989 (CA). A court may only make an adoption placement order if each person with parental responsibility consents, unless the court dispenses with such consent because it is satisfied that the child has suffered, or is likely to suffer, significant harm unless a care order is made and the welfare of this particular child 'requires' her to be adopted - interpreted in case law that 'nothing else will do.'38

For children who are to be adopted as part of a child protection plan, there is a three-stage family court process. First, a care order application is made under the Children Act. ${ }^{39}$ If a care order is granted, the court may make an (adoption) placement order at the same hearing or at a subsequent hearing ${ }^{40}$ Parties to the proceedings are the local authority, the child (represented by a lawyer and a children's guardian (a social worker employed by the Children and Family Court Advisory and Support Service (Cafcass)), and each parent and anyone with parental responsibility. The child will be placed with prospective adopters who will apply to the family court for an adoption order after the child has been with them for a minimum of ten weeks and subject to satisfactory reports from the adoption agency (a local authority or a voluntary sector ( $\mathrm{NGO}$ ) adoption agency). If the child was placed with them under foster care regulations, the required period is 12 months. Until an adoption order is made, those with parental responsibility retain this (shared with the local authority) although it is very restricted. Parents have a right to non-means tested legal representation prior to and during care proceedings. For any subsequent proceedings once the child is in care, there is no absolute right to legal representation and legal aid is usually refused, but parents have a right to be heard, though they may not re-open the decision about consent without prior leave of the court. Alongside the issuing of the legal order, detailed judgements are made orally, summarising the evidence from all parties and the reasoning as to why the child's welfare throughout childhood 'requires' adoption. Transcripts may be requested by the judge or the parties, but costs are a disincentive. Publication

\footnotetext{
38 Supreme Court Re B [2013] UKSC 33.

39 CA, s. 31.

$40 \quad$ Ibid., s. 22.
} 
of redacted judgements on the British and Irish Legal Information Institute (BAILII) website is encouraged by the President of the Family Division, but for privacy reasons or time constraints only a small minority have been made publicly available to date. ${ }^{41} \mathrm{~A}$ placement or adoption decision can only be appealed with leave of the court and requires a hearing. An appeal will only be allowed where a substantial change in circumstances has been demonstrated. A local authority can apply for the repeal of a placement order as well as a parent, and a judge may do so of her own volition if the case comes before her for another reason.

In recent years, the rise in the numbers of children entering care and the accompanying increase in applications for placement orders, especially of very young children, ${ }^{42}$ has led to considerable debate within legal and child protection circles and in the media about the public acceptability of adoption without consent, and to a call for greater transparency. The sharing of any court papers, including by parents, is expressly forbidden other than with specific leave of the court. Since 2009, the press has had access to some family court proceedings but must have the direct agreement of the judge before they can publish any information on a particular case. Since 2018, 'legal bloggers' have also had access under the same conditions. ${ }^{43}$

\subsection{Estonia}

Adoption proceedings in Estonia are regulated by the Family Law Act 2009 (FLA). The decision on the future custody rights over the child is central to the proceedings. Parental consent is not required where the parent is incapable of submitting an application for an extended period of time, for example in coma; the parent's whereabouts are unknown for an extended period of time; or the parent has been deprived of custody rights in full. ${ }^{44}$

Before adoption proceedings can start, the biological parents' rights have to be fully terminated (usually during care proceedings) and custody rights over the child are either given to the local government, or are shared between the local government and the foster parents. At this point, the court will also

41 J. Munby (2014) 'Transparency in the Family Courts. Publication of Judgments. Practice Guidance. 01 January 2019 Retrieved 05 March 2019 https://www.judiciary.uk/wp-content/ uploads/2014/o1/transparency-in-the-family-courts-jan-2014-1-pdf; J. Doughty, I. Reed and P. Margrath, 'Transparency in the Family Courts: Publicity and Privacy in Practice' (London, UK: Bloomsbury Family Law Series 2018).

K. Broadhurst, B. Alrouh, C. Mason, H. Mason, L. Holmes, M. Ryan and S. Bowyer, 'Born into Care: Newborn Babies Subject to Care Proceedings in England. The Nuffield Family Justice Observatory' (London, UK: Nuffield Foundation 2018).

43 Doughty et al. 2018.

44 S. 135, 152(5) FLA. 
inform the biological parents of the pending or potential future adoption, to which the parents have the right to voice their objections. Parties to these proceedings are the biological parents, the child (represented by a lawyer and a guardian $)^{45}$ and the local government. The proceedings end in a resolution, and if the court terminates parental rights in full, adoption proceedings commence. Biological parents have the right to have their objections to adoption heard during these proceedings as well as appeal the decision terminating their parental rights on the ground that they object to a future adoption.

Adoption is initiated by the prospective adopter $(s)^{46}$ and is decided by a single judge in the district courts. The proceedings are investigative in nature and the court hears all parties personally in order to establish the facts. Since 2017, the Social Insurance Board makes the pretrial preparations for adoption and supports the court by submitting relevant background information and a written report on the health, financial situation and housing of the applicant(s), and participates in the proceedings alongside the child's legal guardian who is usually the child protection services (CPS) of the local government. ${ }^{47}$ The Board also provides an opinion on the applicants' suitability as the child's carer. ${ }^{48}$ The judge decides whether all parties concerned meet simultaneously or separately. In most cases, the adoptive parents, the guardian of the child, the Social Insurance Board and possibly an older child will be present. Most commonly the child is heard by the court before the general hearing. The proceedings can be declared closed to the public, for instance, to preserve the confidentiality of adoption. ${ }^{49}$

Adoption is formalised in the written court order, ${ }^{50}$ which must give due consideration to the rights and interests of the biological parents. ${ }^{51}$ The ruling enters into force once it is presented to the adoptive parents; and, if granted, it cannot be appealed or amended unless the consent of one of the parties whose consent is required, is missing. ${ }^{2}$

To protect the secrecy of the adoption, access to the order and the case file is limited to the adoptive parents, the child and officials who enter the information into the public databases. ${ }^{53}$ If the case reaches the Supreme Court, the judgement can be partially published pertaining to the discretion of the court.

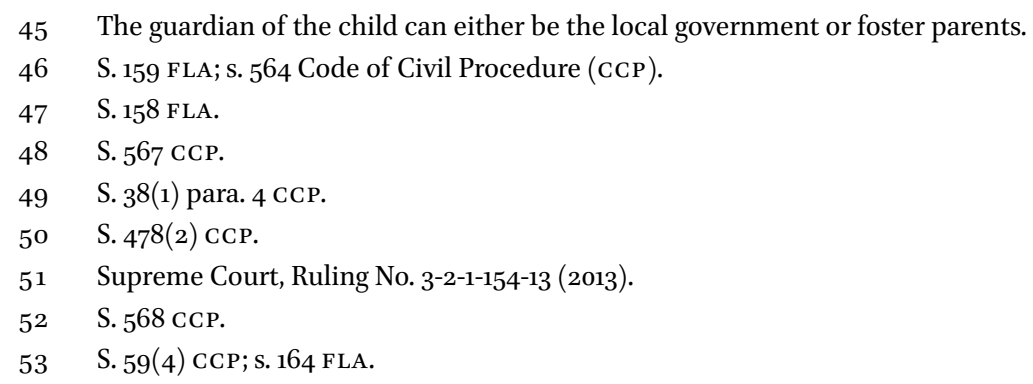


Granting access to the judgments for research purposes is within the discretion of the chief justices of the four district courts; however, there is no established formal procedure for this.

\subsection{Finland}

According to the Adoption Act (AA), ${ }^{54}$ the purpose of adoption is to promote the child's best interests by strengthening the child-parent relationship between the child and the adoptive parents, with the aim to secure a permanent family and balanced development and well-being for a child. ${ }^{55}$ Adoption is typically based on consent given by the parents with legal responsibility for the child and by children who are 12 years or older. In exceptional situations, an adoption may be granted without parental consent, provided that it is in the child's best interests and after due consideration of the nature and quality of the relationship between the birth parents and the child. Municipalities have an obligation to provide adoption counselling to parents giving up their child, the child and future adoptive parents. It is provided by social workers and is a precondition for the initiation of court proceedings. ${ }^{56}$

Adoption decisions are made by the district courts and their legally trained personnel, based on a petition submitted by the future adoptive parents. If the application and related reports are insufficient, the court must gather further information to guide its decision-making. It is not obligatory to organise a hearing, and thus rarely happens, and little is known about this process. The court may meet with the child, parents and guardian face-to-face, to give them the opportunity to be heard. The decision results in a written judgment of approx. one to two pages, and leads to the transferal of parental rights to the adoptive parents. Decisions can be appealed without restrictions to the appeal court, and thereafter on specific procedural grounds to the Supreme Court.

As a general rule, court decisions are public. However, where decisions include sensitive personal information, they are to be kept confidential; thus, adoption decisions are not publicly available and require a permit for access. This is granted by the courts to those with a solid reason for requesting access to the decisions (e.g. researchers). The children, birth parents, adoptive parents and relevant institutions (e.g. social welfare agency) are informed about the adoption decision, and the child and her parents have a right to access the case files of the court. They should be offered necessary support and guidance

\footnotetext{
54 Adoption Act 22/2012.

55 AA §§1-2; Adoption Counseling 2013, 5 .

$56 \quad$ AA §24; Adoption Counseling 2013.
} 
when reading the case files, and their right to access the files may be denied if the information would harm their health or development. ${ }^{57}$

\subsection{Germany}

The German Civil Code (CC) sets out the conditions for adoption. ${ }^{58}$ In principle, adoption is only permissible with the consent of both parents and the child. An exception is regulated in s. 1748 CC, which provides for the substitution of parental consent in adoption proceedings. Only the child can apply for this, but the application is usually filed by a guardian who has been appointed after the removal of custodial rights from the parents. The family court must substitute parental consent to adoption in cases of gross violation of parental duties or parental indifference to the child, where it would be disproportionately disadvantageous to the child if the adoption did not take place; or permanent incapacity for caring for and bringing up the child as the result of a particularly serious psychological illness, or a particularly serious mental or psychological handicap, where the child could not grow up in a family and the child's development would as a result be seriously endangered if the adoption did not take place.

Where the separation of a child from the parents due to an endangerment of the child's best interests ${ }^{59}$ is likely to be permanent, the youth welfare office has an obligation to work towards a permanent family life solution of the child, which includes consideration of adoption. ${ }^{60}$ The Federal Constitutional Court has ruled that adoption by foster parents with whom a child is already placed can be a sensible option. ${ }^{61}$ In practice, parental consent is rarely substituted by the family courts. ${ }^{62}$

Adoption proceedings are handled by the family court. ${ }^{63}$ An adoption without parental consent requires separate proceedings for the substitution of parental consent, which involves a full hearing of the child, the biological parents, the person whose consent is to be substituted, and the adoptive parents. ${ }^{64}$ The hearing of the child may only be omitted where it would be detrimental to her development, education, or health, or if due to her young age,

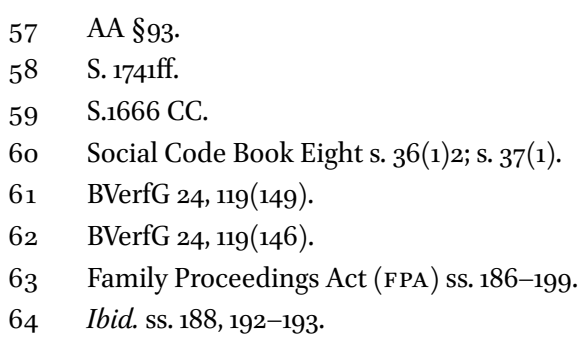


no information can be expected from such hearing. The court has discretion to hear the parties separately where this is necessary for the protection of a party or other reasons. ${ }^{65}$ If a decision to substitute parental consent is made by the court, adoption proceedings follow.

In adoption proceedings, the judge has to hear the child as well as the adoptive applicants in person; the essential results of the hearing are documented during the hearing, usually through an audio recording which is later transcribed. In case of a conflict of interest between the child and the custodial parent or legal guardian, a children's guardian is appointed. ${ }^{66}$ The hearing takes place in a closed session. The written judgement is served to the participants, the youth welfare office and the children's guardian. The written judgement provides the court's reasoning and justification for the decision, as well as the facts and circumstances leading to the decision and the applicable legal basis. In cases of disagreement between the parties, the reasoning is substantial. If all parties agree to the adoption, reference to the professional opinion of the youth welfare office is sufficient.

The child, parents and adoptive parents, the youth welfare office and the children's guardian have a right to appeal to the higher regional court as second instance court. The latter conducts a full taking of evidence and hears the participants again. A further appeal to the Supreme Court is admissible if the higher regional court has given leave to appeal. The proceedings at the Supreme Court are written procedures and decisions are always published. In contrast, family court judgements are only publicly available if the court has released an anonymised version for publication at the judge's discretion. The judge may also decide to impose the costs of the proceedings on the participants but not on the child; parents are usually not charged and may receive means tested legal aid. ${ }^{67}$

\subsection{Ireland}

The Adoption Authority of Ireland (AAI) established in 2010, is an independent regulatory administrative body, responsible for all adoption matters, including the granting of adoption orders.

Applicants participate in an intensive assessment of eligibility and suitability by an accredited body, usually an adoption service which is normally social-work led. Adoption assessments are undertaken by the Child and Family Agency (Tusla) and other accredited bodies. The assessment report is first

\footnotetext{
65 Ibid. FPA s. 33.

$66 \quad$ Ibid. s. 191.

$67 \quad$ Ibid. s. 81.
} 
considered by a Local Adoption Committee, and if they are satisfied, is forwarded to the AAI with a recommendation. There are seven multi-disciplinary members of the AAI board, with a mix of social work, child protection, legal and psychological/psychiatric expertise. The AAI then verify that the adoption assessment, Local Adoption Committee's recommendation and accompanying documentation are in order, before making a recommendation that the adoption application proceeds to the final adjudication state. At the final stage, if the AAI board is satisfied, they will issue a declaration of eligibility and suitability. The hearing is recorded and then transcribed. There can be a number of AAI adoption order hearings in each case with reviews of paperwork and oral inputs from professionals, parents and the child, but the final confirmation hearing with the child present is very short, typically lasting only a few minutes. Adoptive parents and the child must attend the final hearing, and other family members can also attend (e.g. siblings, grandparents). Most adoptions in Ireland are by parental consent, and are mostly stepparent adoptions. The adoptive parents are provided with a letter confirming that the adoption order has been made, the child's old birth certificate becomes void, and a new entry is made in the Adopted Children Register in the General Register Office. ${ }^{68}$

AAI adoption order decisions are provided orally and a two to five-page written determination setting out the basis for granting an adoption order is placed on the file. There is no established formal procedure to make adoption records available to researchers or anyone else, but access for researchers is currently being explored by the AAI board. Members of the media and researchers are allowed to attend adoption hearings with the consent of family members and the chair, but this has not yet happened. An adoption order decision by the AAI can be judicially reviewed upon application to the High Court. A judicial review is normally concerned with the procedural legality of a decision of a lower court, tribunal or administrative body, but in limited circumstances, the substance of a decision may also be examined. ${ }^{69}$

If a parent does not consent to an adoption, is unavailable to consent or does not respond to the AAI, the Child and Family Agency (Tusla) can apply to the High Court for an order to dispense with parental consent in the context of the adoption order application..$^{70}$ The application to the High Court only

\footnotetext{
68 Adoption Authority of Ireland 2017.

69 Law Reform Commission, 'Consultation PaperonJudicial Review Procedure' 2oJanuary 2003. Retrieved 15 May 2019 https://www.lawreform.ie/news/consultation-paper-on-judicial -review-procedure.678.html.

70 Tusla Child and Family Agency [2018] 'Annual Review on the Adequacy of Child Care and Family support Services Available'.
} 
proceeds after the AAI provide their consent and the AAI acts as the respondent in the case. The High Court only addresses the issue of parental consent: the adoption application and adoption orders are the sole preserve of the AAI. A High Court hearing, involving birth parents, adoptive parents and Tusla (all represented by lawyers), which is adversarial in nature, is undertaken to decide if a non-consent should be set aside. Such High Court applications are rare, and the conclusion is normally an oral judgement, although there may occasionally be a written judgement made publicly available. High Court decisions can be appealed to the Court of Appeal, and then on strict limited grounds of exceptional circumstances, to the Supreme Court. In the absence of parental consent or a High Court order setting aside a parent's consent, an adoption application cannot proceed. Where an application has been made to the High Court, the adoption application is suspended until the court proceedings are finalised. Once 28 days have elapsed after the High Court order, the AAI are entitled to proceed to make an adoption order.

\subsection{Norway}

The Adoption Act of 2017 states in section 1 that "The purpose of the act is that adopted children should be given a safe upbringing by establishing permanent legal ties that correspond to the relationship between children and parents." The criteria for an adoption against the parents' will is outlined in the Norwegian Child Welfare Act, ${ }^{71}$ and an application is prepared by the child protection agency. Only foster parents can adopt a child from care. All decisions about adoptions are made by the County Social Welfare Board (County Board).$^{72}$ The County Board is an independent court-like administrative body that operates as a court, and its procedural rules are largely based on the Dispute Act (2005), which also guides court procedures. The County Board is purely a decision-making body; thus, the necessary professional case preparation is undertaken by the child protection agency, although the County Board may also appoint an independent expert if deemed necessary. The general rule is that the County Board is composed of three decision makers, each representing a

71 Norwegian Child Welfare Act of 1992, section 4-20.

72 For a detailed outline of child protection removal proceedings, see M. Skivenes and K.H. Søvig 'Norway - Child welfare decision-making in cases of removals of children' in Burns, K. Pösö, T. and Skivenes, M. (eds.) (2016) Child Welfare Removals by the State: A CrossCountry Analysis of Decision-Making Systems. New York, NY: Oxford University Press, 3, 40-64. A detailed overview of how adoption from care is practiced in Norway is presented in H. S. Helland and M. Skivenes, Adopsjon som barneverntiltak. (Bergen: Universitetet i Bergen 2019). 
different knowledge base, ${ }^{73}$ and each equal in their influence and decisionmaking authority. ${ }^{74}$ The typical proceedings would be a hearing of two-three days, in which private and public parties with their respective lawyers present their arguments. Witness testimonies from both parties will be heard, and the board members may ask questions. The hearing will be closed for the public, but researchers and journalists and possible others may sit in based on an informed consent from private parties and approval by the chair. After the hearing, the board members will deliberate and make a decision. The chair writes the judgment, typically around 12-20 pages, which is confirmed and signed by the other members. All decisions by the county board may be appealed to the district court, and thereafter on selected grounds to the appeal court and Supreme Court. All decisions are stored electronically, and around $6-10 \%$ of the judgements are de-identified and published in the electronic database, 'Lovdata'. It contains all court judgements decided in the last 12 months, but older judgements and child protection judgements are only available at a yearly fee of about 1,200 Euros. Universities and news outlets would typically subscribe to this service, but others would not. Parent and children may talk about and share their documents, but within the restrictions on sharing information about the child. Media in Norway is overall careful in their use of names and approach to children in child protection cases. ${ }^{75}$

\subsection{Spain}

Adoption is established in the Spanish Civil Code, Art. $175^{-180}$, and is a family law act and not directly connected to child protection. Adoption orders are made by judicial resolution, which requires consideration of the best interests of the child and the suitability of the prospective adopters for the exercise of parental authority. The public entities of the autonomous region responsible for the protection of minors - Child Protection Services (CPS) - handle the adoption process and bring the adoption request to court through the Child Custody Commission. This Commission ${ }^{76}$ is a seven-member collegiate body and is the highest decision-making body in the autonomous region of Madrid

73 The three knowledge bases are law, child development and a lay member.

74 Cf. M. Skivenes and M. Tonheim, 'Improving Decision-Making in Care Order Proceedings: A Multijurisdictional Study of Court Decision-Makers' Viewpoints' Child \& Family Social Work 24(2) (2018) 173-182.

75 M. Skivenes and Ø. Tefre, 'Error and Mistakes in Norwegian Child Protection', in: K. Biesel, J. Masson, N. Parton and T. Pösö (eds.) Errors and Mistakes in Child Protection: International Discourses, Approaches and Strategies (In Press).

$7_{6} \quad$ La Comisión de Tutela del Menor. 
in relation to child protection measures. In deciding whether to allow the adoption proposal or not, the judge undertakes her own investigation. Prospective adopters have to obtain a prior declaration of suitability by applying to the relevant CPS. Although adoptions generally require the consent of the parents, the law provides for cases where parents are unable to consent to an adoption. ${ }^{77}$ In addition, CPS may consider a child abandoned when the parents (1) fail to recognise the problem; (2) deny the negative influence on the minor; (3) reject support measures; (4) fail to meet the child's needs; or (5) there is an endangerment situation for the child.

The process from child removal to effective adoption can be lengthy, especially in cases of involuntary placement. Adoption proceedings typically start with the termination of parental rights by the Commission. Prior to the presentation of the adoption proposal to the court, the CPS commonly delegates custody 'for the purpose of adoption' to a child care centre or foster family until the judicial decision of adoption is issued. ${ }^{78}$ This involves an administrative decision following a hearing of the parties, including the minor if she is over the age of twelve years or is sufficiently mature. The CPS meets individually with each party, and thereafter presents the written material and the case for the Commission to consider and to decide on the removal of all parental rights for the purpose of adoption. Parents, as well as the public prosecutor for minors, are notified of the decision. Parents have a right to appeal the removal of parental rights to the family court for up to two years. Thereafter, the child will either be adopted or will be a ward of the state.

Within three months after the decision by the Commission, the CPS sends the complete file along with a three-page proposal to the family court to initiate adoption proceedings. The adoption proceedings are initiated and carried through even though the parents have a two-year appeal period. Adoption decisions are court orders issued by a judge following separate hearings with the adopting parents and the child over twelve years old, or younger if sufficiently mature. Children are heard in safe and private conditions. Though it is not mandatory to hear biological parents who have lost their parental rights, in practice, the judge usually decides to hear their views. The judge can commission any additional expert evidence required, before issuing a court order ratifying or dismissing the initial CPS proposal for adoption. If the proposal is dismissed, adoption will not take place and the child remains in foster care or in a childcare centre.

Adoption appeals are made to the family court in the first instance and to the region's court in the second instance. An appeal may be made on all grounds,

77 Spanish Civil Code, Art. 177.

78 Ibid. Art 176. 
and the case will be heard by four or five judges at each instance. If the parents have not appealed the termination of their parental rights within two years, the adoption process will be completed. In general, observers are not allowed during the process (e.g. researchers and media), but an access permit may be requested from the General Council of Judges, stating the importance of that observer being present for the decision.

The written decision is sent to the parents, the adoptive parents, the public prosecutor and the CPS; and the decisions are not publicly available. All case files, including those from the CPS and the final adoption decision from the court, are stored both by the regional CPS and the family court. Before 2015, it was difficult to access these decisions for public accountability due to children's privacy. However, Law 26/2015 and Organic Law 8/2015 on the modification of the child protection system have emphasised the importance of evaluation for public accountability, opening up the possibility of researchers accessing these decisions in the future.

\subsection{Summary of Findings from the Countries}

Although it is possible in all eight countries in our study to grant an adoption without parental consent, this rarely occurs in Austria, Finland, Germany and Ireland, and to a varying degree in England, Estonia, Norway and Spain. These consent-based systems in Austria, Germany, Finland and Ireland are deviating from the others (although Finland is consensus-driven on all types if interventions). In Ireland, the High Court decides on any issue of parental non-consent, but the administrative decision-making body decides on the adoption. In Spain, it is an administrative decision by the Child Custody Commission to free a child for adoption, which must then be decided by the court. Thus, Ireland and Spain have distinctly different proceedings in these cases, as there are two decision-making bodies involved in the process.

Adoption from care proceedings typically start with some restriction of parental rights and a corresponding (partial) transfer of responsibility for the child to the child protection system. ${ }^{79}$ Thus, the decision that an adoption should be pursued is made while the child is already under state care; in some jurisdictions, the exploration of adoption as a means to secure a permanent family situation for the child is recommended by the law (e.g. Germany, England). With regard to the adoption from care process, we found significant procedural variation between the eight jurisdictions.

The need for identified prospective adopters varies: In England, and in practice in Estonia (where parental rights are often fully terminated in the 
care order proceedings), a child may be placed for adoption in the absence of known adopters. This is not possible in any of the other countries, and may have implications for who can apply for an adoption, and for the focus of the adoption proceedings. In Estonia and Finland, only the prospective adoptive parents can initiate an adoption from care. In these situations, the adoption application and the decision-making process tend to involve an assessment of the adoptive parent's suitability in general and specifically in relation to the child concerned, and less on birth parents' rights and past events.

In all countries except Estonia and Spain, the decision about granting an adoption and terminating parental rights is made at the same decision-making point. However, in four countries (Austria, Finland, Ireland and Norway) the decision to terminate all parental rights and the decision to grant an adoption are made at the first decision point (\#C. in Table 4). This means that these countries have a single decision-making point for both the termination of parental rights and the adoption (although for Ireland dispensing a non-consent is decided by the High Court). In the other four countries, it is first decided that the child may be adopted (England), that parental consent may be substituted (Germany), or parental rights are fully terminated, and the child is freed for adoption (Estonia and Spain). Thereafter, for these four countries, there is a consecutive decision-making point (\#D.) in which parental rights are terminated and an adoption is decided (England, Germany and Spain), or an adoption is decided (Estonia). The adoption, once granted, severs all legal ties between a child and her biological parents; although in Austria, limited obligations remain. ${ }^{80}$

\section{Discussion}

Moving over to the accountability conditions set out in Table 1, we found that although a common approach could be identified for all seven criteria, each of them had at least one outlier country. ${ }^{81}$ In most of the countries, the parties concerned meet in a hearing in front of the decision maker at the same time. In Estonia, it is within the judge's discretion whether a joint meeting with all

8o Adopted children may inherit both from their adoptive and their biological parents (Austrian Civil Code, §199) and birth parents remain the child's parents within the construct of the subsidiarity principle, which means that, for example, if something happens to the adoptive parents and the adopted child needs to be moved into residential care, the birth parents will be liable to pay child support for the child (Austrian Civil Code, §198).

81 cf. Appendix, \# 3 and \#4. 
TABLE 4 Process flow: Adoptions from care without parental consent

\section{Process Country specific information}

A. Starting point: CPS has respon- Starting point for all countries. sibility for a child, and there are restrictions on parental rights (PR). A decision is made that an adoption should be pursued

B. An adoption application is prepared by CPS, or an application is prepared by adoptive In practice, adoptions are typically by consent from parents in Austria, Finland, Germany, Ireland parents.

C. Decision-making body decides about termination of PR or severe restriction of PR (England, Germany) with the aim for adoption; or frees the child for adoption (Estonia); or decides an adoption and TPR (Austria, Finland, Ireland, Norway). By CPS: Austria, England, Germany, Ireland, Norway, Spain

By future adoptive parents: Estonia, Finland

Final decision-making point here

Austria District court TPR, Adoption

England Family court Placement order, RPR

Estonia District court TPR

Finland District court TPR, Adoption

Germany Family court Substitution of

at C. for Austria, Finland, Ireland, and Norway. parental consent, RPR

Ireland $\mathrm{AAI}^{\mathrm{a}}$ TPR, Adoption

Norway County TPR, Adoption

D. Final decision about adoption, or TPR and adoption; made by the same decision-making body as under C. (England, Estonia, Germany), or by another decisionboard

Spain Commission Freed for adoption, $T P R^{b}$

England Family court TPR, adoption Estonia District court Adoption Germany Family court TPR, adoption Spain Familycourt Adoption making body (Spain).

$\mathrm{PR}=$ parental rights; $\mathrm{TPR}=$ termination of parental rights; $\mathrm{RPR}=$ restricted parental rights; $\mathrm{CPS}$ $=$ Child Protection Service

a In Ireland, all adoptions are decided by AAI, but where adoption is appropriate, but parents do not consent, the High Court must decide if parental consent should be dispensed with in a particular case.

b In Spain, parents may appeal the decision to end PR for a period of two years. 
parties is held, or if the parties are met separately. In Finland, however, meetings rarely take place at all and a substantial part of the case is treated without a formal hearing. Instead, the parties concerned will have been heard during adoption counselling. Oral hearings typically take place with all the parties concerned, i.e. the CPS, birth and adoptive parents, and the child, as well as the parties' legal representatives. Estonia is the exception, as only the CPS, the adoptive parents, the child and the child's legal representative are invited to a hearing.

Judgements are in writing in seven of the countries, but with huge variations in terms of length, content and style. In England, the oral hearings are recorded but only transcribed at the request of one of the parties or at the discretion of the judge. The recipients of the decision are the same as the parties that attended the hearing, but the adoption agency or adoption branch of the CPS will also receive the decision. The records of the decisions, whether a court judgment or other document, include the reasoning behind them in all eight countries. They refer to the relevant legal provisions, applied to the facts of the case, which always involves some discussion of the principle of the child's best interests in the context of the anticipated adoption. However, the background information and justifications provided vary greatly. For instance, the judgements in Estonia and Finland focus primarily on the suitability of the prospective adoptive parents, and not so much on the history of the child within her birth family. In Germany and Ireland, where the issue of parental consent is addressed in separate proceedings before adoption proceedings can be initiated, the focus is initially on justifying the pursuit of adoption without parental consent.

An adoption order can be appealed in all eight countries. Five countries require specific reasons for the appeal, such as a procedural violation, or only allow it where the adoption order was not granted by the court (Estonia). Germany, Finland and Norway impose no restrictions and allow appeals without specific reason.

Adoption decisions are generally not publicly available, with only two countries publishing a non-representative selection of their decisions in anonymised form online (England, Norway). The process for selecting judgements is not transparent in either country. In Germany, judges may select individual judgments for publication; however, this is rarely practiced by first instance courts. Finally, practical obstacles to accountability may exist at two levels. First, with regard to the adoption from care proceedings, high cost of legal support and lack of legal aid (England) or costs imposed by the judge during court proceedings (Germany) could impact accountability on an individual case level. In addition, on a more general level, accountability may also be hampered 
by the fees payable by ordinary citizens to access judgements (Norway), and by the discretionary decision-making with regard to access in the absence of clear and transparent procedures for legitimate research requests (all countries).

Adoption from care is an intrusive state intervention into individuals' private sphere, hence it is immensely important that the decisions made are qualified and can withstand critical scrutiny. The decision-making bodies in the adoption proceedings are the defined "actors" in our analysis, and they should answer to a "forum" that we have defined as a) the elected government, b) the public (i.e. citizens and the media), and c) the parties concerned in any particular case. In the following, we address three questions: 1 . How is the actor informing the forum, if at all? 2. May the forum question the process and the justifications? 3 . Is there any possibility for the forum to pass a judgment on the actor? In short, we examine if and how the established systems for decision-making, and the decisions on adoptions, are justified in democratic states.

\subsection{Is the Actor Informing the Forum?}

The possibilities for informing the forum about how, why and on what grounds a decision has been made, is overall very limited. Citizens, politicians, and the government, do not have direct or indirect access to adequate information about decision-making processes concerning adoptions from care. With a few exceptions, it is only the parties concerned in the particular case that are informed, and only a few systems allow researchers and/ or the media to be present. Citizens, the general public, and politicians will only have an opportunity on a general basis to inform themselves about the content of adoption proceedings in Norway and England, as written judgments are available on a regular yearly basis for the public, in de-identified form. And, in Norway, this comes with a price tag. However, the selection of the non-representative sample of decisions that become publicly accessible is not transparent. Adoption decisions are presented in a written format in all countries (whether easily accessible or not), except in England, where the full judgement will be in writing if someone requests it. Although the parties themselves (except in England and Ireland) may give access to documents and bring forward their experiences to the forum, it is a weak accountability mechanism in the sense that individual cases lack generalized information about the system and its practice. However, individual cases displayed in the media may have a huge influence on public meaning formation and the ability to change law and practice. In most countries, there is a practice that decisions from the higher courts are made public, but also these cases provide only a limited basis for insight into the system and its practice, and typically focus on specific legal dilemmas and puzzles. 


\subsection{May the Forum Question the Process and the Justifications?}

We found very limited possibilities for the forum to interrogate the actor and to obtain explanations and answers from the actor. For those countries where the judiciary are the decision-makers in adoption cases, this may be partially explained by the judiciary's independence and the fact that they cannot be instructed. Three limited channels for inquiries emerged in our research. First, the parties concerned, and their legal representatives can ask questions during the proceedings, within the legal framework and at the decision-maker's discretion. This presents a very limited opportunity for review of the proceedings, as it is only the stakeholders in the case that are present. Furthermore, in two countries it is normally only the child and the adoptive parents that are present in court or a decision-making body (Estonia, and Ireland), meaning that others directly or indirectly affected by the decision are deprived of an opportunity to interrogate the decision-maker and the process. The biological parents will have been engaged with at some point in the adoption process in all countries (if they are available), at a minimum, in terms of expressing their consent for the adoption. We find it less likely that the parties concerned are in a position to ask critical questions concerning legitimacy, if, for example, they are in doubt about the legitimacy of the decision-makers' exercise of discretion. While legal representatives for the parties may serve to ensure the rightfulness and legality of court actions, this presupposes that all parties are represented by lawyers, which may depend on the particular legal system, including any financial support available for such representation. Second, in three countries (Ireland, Norway and Spain), there is more than one decision maker and thus a possibility for an internal review of the decision-making. Third, there are also possibilities for external parties, such as the press and researchers, to be present in the decision-making forum, although it depends on the consent of parent, child and/or the judge/chairperson. In England, the press and legal bloggers have the right to attend family proceedings but not to report on them without the express consent of the judge which is only given in exceptional cases. In practice, it appears that there is a high threshold set for access to these types of decision-making fora. In liberal democracies, there is an established role for responsible members of the press and bone fide researchers to perform this task on behalf of society. Thus, in most countries, decisions about adoption from care do not appear to adequately answer to a forum of citizens and public reasoning.

\subsection{Can the Forum Pass Judgement on the Actor?}

In a constitutional democracy, the courts are independent and shall not be directly sanctioned for their decision-making. Still, we may ask if there are any 
possibilities to make the courts and court-like decision-making bodies answer for their decision-making to a forum. Our findings show that there are only a few mechanisms in place, all within the judiciary system. Rather than providing a means for directly sanctioning the court, these mechanisms rely on established legal procedures of appeal and constitutional complaint. Thus, with regard to the question if decision-makers will face any consequences of a wrong, unjust or poorly argued decision, the legal system requires that only the appellate courts can make the decision-makers face any consequences. The primary oversight mechanism is that a decision might be overturned on appeal, which is a serious consequence and an important corrective. However, in most countries the right to appeal requires specific reasons (except in Finland, Germany and Norway), thus providing only a limited opportunity for a review of the case. Costs may also be a disincentive for appeal (England). Nevertheless, we do assume that decision-makers experience a form of indirect review and oversight, as we assume that they are concerned that the scrutiny that follows an appeal will reveal deficits with the decision-making, and therefore indirectly functions as an accountability mechanism. However, it remains a fact that there are no possibilities for directly holding decision-makers accountable for poor decision-making, at least not where these are part of the judiciary. Exceptionally, members of the judiciary may face personal consequences for deliberate or grossly negligent wrongdoing, but since this has significant potential to compromise the state of the law and the independence of the judiciary, this only occurs in isolated and serious cases. Where the decision-maker is an administrative body and its members are registered professionals (e.g. lawyers, social workers, psychologists, etc.), sanctions for misconduct may be imposed by the professional regulatory body. Members of such professions may thus face disciplinary action or may even be struck off the register, but individual judgments cannot be interfered with.

The reality of our analysis is discouraging, as there is only limited accountability for one of the most intrusive interventions by a state into the private lives of individuals. There is not only a lack of information about the system and the proceedings, but there is also an alarming lack of transparency and a veil of secrecy. We have portrayed systems that to a large degree and with few exceptions operate in isolation, with only a few outsiders having access or knowledge about what is going on. It is the missing connection between the wider democratic society and this part of the legal systems that is of concern 
to us. The paradox is that public debates on child protection in many countries are overwhelmed by huge amount of misinformation and public distrust, but we have very little oversight and insight into how adoptions from care are decided upon. It appears to be a case of unsubstantiated trust in the efficiency of the rule of law, the representation by lawyers, judicial independence and the corrective of the appeal stages within the judicial system. Furthermore, the fact that we do not have sufficient information to determine if the consensual adoptions from care are based on an actual informed consent is troubling. The European Convention on Human Rights states in Article 8, the right to private and family life, that intrusive interventions are only legitimate if they are according to the law and can be considered necessary in a democratic society for the protection of other interests. Yet, in the eight democracies we studied, we were not able to substantiate that there are sufficient accountability mechanisms in place to know if adoption from care proceedings are legitimate.

The systems may produce rational and reasoned decisions that will stand the scrutiny of a forum, but as it is now, we do not know much about this. We are aware of the difficult balancing act involved in managing the tension between confidentiality and privacy rights on the one hand, and transparency and oversight on the other, and that the rights of the child are a complicating factor in the discussion of openness. The restrictions on sharing information about a child and parents are necessary and right. However, there are ways to make sure both confidentiality and accountability are equally considered. In many ways this is a practical problem that has been solved within other areas of the state, for example, defence, trade secrets, terror protection, as well as within more private domains, such as the health care system, where some health and medical information is shared within the system for accountability purposes. Therefore, while these challenges in reconciling state system transparency with the privacy rights of individuals may explain the limited popular control (democratic perspective), we have also shown that research may play an important role in public accountability of judicial decision-making. Clear and transparent procedures for legitimate research access requests would further enhance the ability of researchers to enhance accountability in important areas of public decision-making. This would also set the basis for a proper checks and balances system (constitutional perspective), which is concerned with the abuse of power. In this context, systematically studying the rights of biological parents and children, including their procedural rights, would be of enormous importance, as it might reveal any irregularities in bringing about decisions (e.g. the question of informed consent).

At present, the only protective mechanism against abuses of power appears to be the limited appeal possibilities to the higher courts, or to professional 
bodies or media. However, unless an appeal reaches the highest court, the remedial effect of a reversed decision would typically only apply to the individual case. Thus, to implement a 'learning effect' and enhance government effectiveness, thorough review processes and a solid feedback system would have to be put into place to ensure that adoptions from care are handled more effectively in the future (learning perspective). While the CPS in the countries studied often tends to operate under some hierarchical or regional structures, which may involve internal reviews of decisions made, the same cannot be said for the decisions of the judiciary. This missing feedback loop from the courts to the government compromises the potential for improvement in this particularly sensitive area of state intervention. 